\title{
Article \\ Nuclear Localization Sequence of FGF1 Is Not Required for Its Intracellular Anti-Apoptotic Activity in Differentiated Cells
}

\author{
Agata Lampart ${ }^{1}$, Katarzyna Dominika Sluzalska ${ }^{1}{ }^{\oplus}$, Aleksandra Czyrek ${ }^{2}{ }^{\circledR}$, Aleksandra Szerszen ${ }^{1}$, \\ Jacek Otlewski ${ }^{1}\left(\right.$, Antoni Wiedlocha ${ }^{3,4}$ and Malgorzata Zakrzewska ${ }^{1, *(1)}$
}

1 Department of Protein Engineering, Faculty of Biotechnology, University of Wroclaw, ul. F. Joliot-Curie 14a, 50-383 Wroclaw, Poland; agata.lampart@uwr.edu.pl (A.L.); katarzyna.sluzalska@uwr.edu.pl (K.D.S.); aszerszen00@gmail.com (A.S.); jacek.otlewski@uwr.edu.pl (J.O.)

2 Department of Protein Biotechnology, Faculty of Biotechnology, University of Wroclaw, ul. F. Joliot-Curie 14a, 50-383 Wroclaw, Poland; aleksandra.czyrek@uwr.edu.pl

3 Department of Molecular Cell Biology, Institute for Cancer Research, The Norwegian Radium Hospital, Oslo University Hospital, Montebello, 0379 Oslo, Norway; antoni.wiedlocha@ous-research.no

4 Centre for Cancer Cell Reprogramming, Institute of Clinical Medicine, Faculty of Medicine, University of Oslo, Montebello, 0379 Oslo, Norway

* Correspondence: malgorzata.zakrzewska@uwr.edu.pl; Tel.: +48-713-752-889

check for updates

Citation: Lampart, A.; Sluzalska, K.D.; Czyrek, A.; Szerszen, A.; Otlewski, J.; Wiedlocha, A.; Zakrzewska, M. Nuclear Localization Sequence of FGF1 Is Not Required for Its Intracellular Anti-Apoptotic Activity in Differentiated Cells. Cells 2022, 11, 522. https://doi.org/ $10.3390 /$ cells 11030522

Academic Editor: Igor A. Prudovsky

Received: 22 December 2021

Accepted: 31 January 2022

Published: 2 February 2022

Publisher's Note: MDPI stays neutral with regard to jurisdictional claims in published maps and institutional affiliations.

Copyright: (C) 2022 by the authors. Licensee MDPI, Basel, Switzerland. This article is an open access article distributed under the terms and conditions of the Creative Commons Attribution (CC BY) license (https:// creativecommons.org/licenses/by/ $4.0 /)$.

\begin{abstract}
Fibroblast growth factor 1 (FGF1) is considered primarily as a ligand for FGF surface receptors (FGFRs) through which it activates a number of cellular responses. In addition to its canonical mode of action, FGF1 can act intracellularly, before secretion or after internalization and translocation from the cell exterior. The role of FGF1 inside the cell is to provide additional protection against apoptosis and promote cell survival. The FGF1 protein contains a specific N-terminal nuclear localization sequence (NLS) that is essential for its efficient transport to the nucleus. Here, we investigated the role of this sequence in the anti-apoptotic response of FGF1. To this end, we produced recombinant FGF1 variants with mutated or deleted NLS and added them to apoptosis-induced cells in which FGFR1 was inactive, either as a result of chemical inhibition or kinase-dead mutation. After internalization, all FGF1 variants were able to protect the differentiated cells from serum starvationinduced apoptosis. To verify the results obtained for NLS mutants, we knocked down LRRC59, a protein that mediates the nuclear transport of FGF1. Upon LRRC59 silencing, we still observed a decrease in caspase 3/7 activity in cells treated exogenously with wild-type FGF1. In the next step, FGF1 variants with mutated or deleted NLS were expressed in U2OS cells, in which apoptosis was then induced by various factors (e.g., starvation, etoposide, staurosporine, anisomycin and actinomycin D). Experiments were performed in the presence of specific FGFR inhibitors to eliminate FGFR-induced signaling, potentially activated by FGF1 proteins released from damaged cells. Again, we found that the presence of NLS in FGF1 is not required for its anti-apoptotic activity. All NLS variants tested were able to act as wild type FGF1, increasing the cell viability and mitochondrial membrane potential and reducing the caspase 3/7 activity and PARP cleavage in cells undergoing apoptosis, both transiently and stably transfected. Our results indicate that the nuclear localization of FGF1 is not required for its intracellular anti-apoptotic activity in differentiated cells and suggest that the mechanism of the stress response differs according to the level of cell differentiation.
\end{abstract}

Keywords: FGF1; translocation; intracellular FGF1; nuclear FGF; nuclear localization sequence; anti-apoptotic activity

\section{Introduction}

Fibroblast growth factor 1 (FGF1) acts through specific interactions with surface FGF receptors (FGFRs) to activate intracellular signaling axes, such as PLC $\gamma /$ PKC, PI3K/Akt, and Ras/MAPK, regulating cell growth, proliferation, survival, and playing a significant role in development [1-3]. In addition to this canonical modus operandi, FGF1 has the 
unique ability to translocate across cell membranes, reaching the cytosol and then nucleus [4-8]. In the early 1990s, Imamura and coworkers discovered that FGF1 has a specific $\mathrm{N}$-terminal nuclear localization sequence (NLS), which is essential for efficient transport of FGF1 to the nucleus and its mitogenic activity $[7,8]$. Interestingly, the selected monopartite sequence NYKKPKL (residues 21 to 27) was similar to the NLSs of other nuclear proteins such as c-myb, N-myc, p53 and c-erb-A [9,10]. However, later studies have shown that deletion of this signal sequence results in loss of the protein stability, protease resistance and reduced affinity for FGFRs [11], which could explain it impaired biological activity. When point mutations were introduced in the NLS of FGF1, they do not affect FGF1 ability to stimulate mitogenic response $[12,13]$.

Over the years, reports of evidence for nuclear translocation of FGF1 began to emerge, laying the groundwork for elucidating its mechanism. Stress conditions including serum starvation, oxidative stress, and hyperosmolarity have been shown to promote FGF1 translocation in the G1 phase of the cell cycle [14-16]. Only two FGF receptors (FGFR1 and FGFR4) are able to mediate this process [15].Moreover, the presence of a specific sequence within the C-terminus of the receptor is required for the FGF1 translocation, whereas the active kinase domain of the receptor appears to be irrelevant in thisprocess $[15,17,18]$. Despite ongoing efforts, the exact fate of the FGF1-FGFR complex when crossing the endosomal membrane, as well as the timing of its dissociation, is not yet fully understood.

Nevertheless, it is known that vesicular membrane potential is required for FGF1 translocation from early endosomes [19], and numerous cytosolic molecules such as PI3K [20], HSP90 [21] and p38 kinase [16] are involved in this process. After leaving the endosomes, FGF1 can interact with conventional transport proteins including karyopherin alpha1, karyopherin beta1, exportin-1, Ran, and LRRC59 [22-25]. Of note, interaction with LRRC59 [22] is critical for the nuclear import of exogenous FGF1 [26].

About six hours after FGFR binding, the amount of FGF1 translocated into the nucleus is maximal. In the nucleus, PKC $\delta$ phosphorylates FGF1 at serine 130, providing a signal for FGF1 export back to the cytosol and subsequent degradation [27]. In addition, FGF1 also contains a leucine-rich nuclear export sequence (NES), which is responsible for its nuclear export [25].

In 2005, Wesche et al. described a second NLS of FGF1, a bipartite one characterized by two lysines clusters separated by $10 \mathrm{AA}$. Moreover, both of them are required for FGF1 transport into the nucleus. Several mutations involving the substitution of lysines to alanines were designed. Variants with mutated N-terminal NLS and first cluster of bipartite NLS after addition to NIH 3T3 cells were found in the cytosolic but not in the nuclear fraction [13].

Although the trafficking of internalized FGF1 has been described in some detail, much remains to be uncovered in understanding its intracellular functions. We have recently shown that translocation of exogenous FGF1 protects cells from apoptosis through a pathway independent of FGFR signaling [28]. FGF1, which after internalization crosses the endosomal membrane, exerts an anti-apoptotic effect regardless of receptor activation.

Many studies have also focused on elucidating the neurotrophic and pro-nutritional properties of FGF1. Ectopic expression of FGF1 has been shown to promote neuronal differentiation [29] and inhibit p53-dependent apoptosis in undifferentiated PC12 cells [30,31]. The same group suggested that these features are regulated by C-terminal domain of FGF1 and its phosphorylation [32]. Importantly, deletion of the N-terminal NLS motif of FGF1 resulted in diminished neuronal differentiation and protection from p53-dependent apoptosis [33]. As the stability of the $\triangle \mathrm{NLS}$ variant is arguable, further analyses are required to fully elucidate the role of NLS in the FGF1 function.

Here, we have investigated the role of the NLS motifs in the anti-apoptotic response generated by FGF1. We found that both endogenously and exogenously administrated NLS variants did not show reduced anti-apoptotic activity compared with the wild type in differentiated cells. Even upon LRRC59 silencing, we have still observed a protective effect 
of FGF1. Our results thus indicate that the nuclear localization of FGF1 is not essential for its intracellular anti-apoptotic activity in differentiated cells.

\section{Materials and Methods}

\subsection{Antibodies and Reagents}

Unless otherwise indicated, all reagents were purchased form Merck (Darmstadt, Germany). The following primary antibodies were used: goat anti-FGF1 (sc-1884), mouse anti-FGF1 (sc-55520), and mouse anti-FGFR4 (sc-136988) from Santa Cruz Biotechnology (Dallas, TX, USA); mouse anti- $\gamma$-tubulin (T6557) and rabbit anti-LRRC59 (HPAA030829) from Sigma-Aldrich (Darmstadt, Merck, Germany); rabbit anti-PARP (9542), rabbit antipERK1/2 (9101), rabbit anti-ERK1/2 (9102), rabbit anti-FGFR1 (9740), rabbit anti-FGF1 (3139), and rabbit anti-FGFR2 (11835) from Cell Signaling Technology (Danveres, MA, USA); goat anti-FGF1 (AF232) from R\&D Systems (Minneapolis, MN, USA); mouse anti-lamin A (ab8980)and rabbit anti-FGFR3 (ab10559) from Abcam (Cambridge, UK); rabbit anti-pFGFR1 (06-1433) from Merck (Darmstadt, Germany). Rabbit polyclonal anti-FGF1 antibodies (OMA1) were generated by Davids Biotechnologie GmbH (Regensburg, Germany) by immunization of rabbits with purified FGF1. Secondary antibodies coupled to HRP: donkey anti-mouse (115-035-003), donkey anti-rabbit (111-035-144) and donkey anti-goat (705-035147) were from Jackson Immuno-Research Laboratories (Cambridge, UK). Actinomycin D was from Santa Cruz Biotechnology (Dallas, TX, USA).

\subsection{Cell Lines}

Mouse fibroblast cell line NIH 3T3 (CRL-1658), rat pheochromocytoma cell line PC12 (CRL-1721), human osteosarcoma cell line U2OS (HTB-96), and human embryonic kidneyderived cell line HEK-293 were from ATCC (Manassas, VA, USA). U2OS cell lines stably transfected with wild type FGFR1 (U2OSR1) and K514R variant (U2OSR1_K514R) were kindly provided by Dr. Ellen M. Haugsten from the Department of Molecular Cell Biology, Institute for Cancer Research, Oslo University Hospital. NIH 3T3 cells were grown in Dulbecco's modified Eagle's medium (DMEM; high glucose, w/o sodium pyruvate; Gibco, Thermo Fisher Scientific, Waltham, MA, USA) with 10\% bovine serum (Gibco, Thermo Fisher Scientific, Waltham, MA, USA). PC12 cells were cultured in RPMI 1640 medium (BioWest, Nuaillé France) supplemented with 10\% horse serum (Gibco, Thermo Fisher Scientific, Waltham, MA, USA) and 5\% fetal bovine serum (Gibco, Thermo Fisher Scientific, Waltham, MA, USA). U2OS and HEK-293 cells were cultured in DMEM (high glucose, with sodium pyruvate; Nuaillé BioWest, France) with 10\% fetal bovine serum (Gibco, Thermo Fisher Scientific, Waltham, MA, USA). Stably transfected U2OS cell lines were grown in DMEM with $10 \%$ fetal bovine serum supplemented with $0.5 \mathrm{mg} / \mathrm{mL}$ geneticin (BioShop, Burlington, Canada). All culture media were supplemented with antibiotics $(60 \mu \mathrm{g} / \mathrm{mL}$ penicillin and $100 \mu \mathrm{g} / \mathrm{mL}$ streptomycin) from BioWest (Nuaillé, France). All cell lines were cultured in a $5 \% \mathrm{CO}_{2}$ atmosphere at $37^{\circ} \mathrm{C}$.

\subsection{Expression and Purification of Recombinant Proteins}

Escherichia coli strain B121(DE3)pLysS from Merck (Darmstadt, Germany) was used for FGF1 proteins (wild type and mutational variants) production. A pET-3c vector (Novagen, Madison, WI, USA) containing a DNA fragment encoding Met-Ala-FGF1_22-155 was used to express wild-type FGF1. FGF1 constructs with mutated NLS sequences ( $\triangle$ NLS, NLS1, NLS2A, NLS1,2A $[7,13]$ in the pET-3d vectors were obtained from GeneUniversal (Newark, DE, USA) as a custom gene synthesis. Stabilizing mutations (Q40P, S47I, H93G) [34] were introduced by QuickChange site-directed mutagenesis using mutagenesis primers (Genomed, Warszawa, Poland).Expression and purification of FGF1 variants were performed as previously described [35]. Briefly, E. coli B121(DE3)pLysS cells transformed with plasmids containing FGF1 variant sequences were cultured at $37^{\circ} \mathrm{C}$ to $\mathrm{OD}_{600} 0.8$ in LB medium from BioShop (Burlington, Canada) supplemented with $100 \mu \mathrm{g} / \mathrm{mL}$ ampicillin and $30 \mu \mathrm{g} / \mathrm{mL}$ chloramphenicol. Protein expression was induced by adding IPTG to a final 
concentration of $1 \mathrm{mM}$. After $16 \mathrm{~h}$ of overnight culture at $25^{\circ} \mathrm{C}$, the bacteria were harvested. The bacterial pellet was resuspended in buffer $(20 \mathrm{mM}$ Tris $/ \mathrm{HCl}, 0.1 \mathrm{mM}$ PMSF, $1 \mathrm{mM}$ EDTA, $1 \mathrm{mM}$ DTT, $0.5 \mathrm{M} \mathrm{NaCl}$; $\mathrm{pH}$ 7.4), sonicated and centrifuged. FGF1 proteins were purified from the soluble fraction using a Heparin-Sepharose column with a linear $\mathrm{NaCl}$ gradient. Recombinant proteins were analyzed by SDS-PAGE and mass spectrometry. The secondary and tertiary structures of FGF1 variants were verified by circular dichroism (J-715 or J-815 spectropolarimeter; Jasco, Easton, MD, USA) and fluorescence (FP-750 or FP-8500 spectrofluorimeter; Jasco, Easton, MD, USA) measurements as previously described [34,35].

\subsection{Transfections and Silencing}

The coding sequences of FGF1 variants were also cloned into transfection vector containing the myc tag, pcDNA3.1 (Invitrogen, Thermo Fisher Scientific, Waltham, MA, USA) and later used for transient and stable transfections of cells. PC12 cells were transiently transfected with these plasmids using Lipofectamine LTX with Plus Reagent (Thermo Fisher Scientific, Waltham, MA, USA). U2OS and HEK-293 cells were transfected using FuGene HD transfection reagent (Promega, Madison, WI, USA) according to the manufacturer's protocol. For transient transfections, cells were seeded onto plates $24 \mathrm{~h}$ before transfection and experiments were performed 24-72 h after transfection. Stably transfected U2OS cells were re-plated $24 \mathrm{~h}$ after transfection and cultured in selection medium (with additional $0.5 \mathrm{mg} / \mathrm{mL}$ geneticin) until colony formation was observed. Cloning discs were used to transfer colonies to 6-well plates, and then cells were transferred to T-75 $\mathrm{cm}^{2}$ flasks or experimental plates. In all cases, expression of FGF1 variants was verified by Western blotting with anti-FGF1 antibodies.

Silencing of LRRC59 in U2OSR1 cells was performed with siRNA against LRRC59 (Eurofins MWG Operon, Eserberg, Germany) [26] or non-targeting siRNA (Horizon, PerkinElmer, Boston, MA, USA) using DharmaFECT transfection reagent (Horizon, PerkinElmer, Boston, MA, USA) according to the company protocol. Experiments were performed $72 \mathrm{~h}$ after silencing. The level of knockdown was confirmed by Western blotting using antiLRRC59 antibodies.

\subsection{Subcellular Fractionation}

U2OSR1 were starved for $24 \mathrm{~h}$ and stimulated with mutated variants and wild type FGF1 $(100 \mathrm{ng} / \mathrm{mL})$ in the presence of heparin $(10 \mathrm{U} / \mathrm{mL})$. Bafilomycin A1 $(10 \mathrm{nM})$ was used as a control for inhibition of the translocation process. For fractionation into membrane, cytosolic and nuclear fractions, we used a digitonin-based method, described previously [27]. Cells incubated with FGF1 for $6 \mathrm{~h}$ were washed with HSLP-buffer (high-salt/low-pH buffer; $2 \mathrm{M} \mathrm{NaCl}, 20 \mathrm{mM}$ sodium acetate; $\mathrm{pH} 4.0$ ) to remove surface bound FGF1. Cells were permeabilized with $20 \mathrm{ug} / \mathrm{mL}$ digitonin in PBS and incubated first at $25^{\circ} \mathrm{C}$ for $5 \mathrm{~min}$ and then on ice for a further $30 \mathrm{~min}$, allowing the cytosol to be released. The solution was collected and represented the cytosolic fraction. Cell debris was lysed in lysis buffer $(0.15$ $\mathrm{M} \mathrm{KCl}, 40 \mathrm{mM}$ Tris, 1\% Triton X-100 and 2 mM EDTA; pH 7.2), centrifuged and supernatant was determined as the membrane fraction. Insoluble material was sonicated and designated the nuclear fraction. To fractionate cells into two fractions (cytoplasmatic and nuclear), cells were washed with PBS and lysed in a lysis buffer (20 mM Tris, $150 \mathrm{mM} \mathrm{NaCl}$, $1 \mathrm{mM}$ EDTA, 1\% Triton X-100; $\mathrm{pH} 7.5$ ) containing protease inhibitor cocktail for $20 \mathrm{~min}$ on ice. The lysates were then centrifuged for $5 \mathrm{~min}$ at $17,000 \times g$ at $4{ }^{\circ} \mathrm{C}$. The Triton X-100 soluble fraction was collected as the cytoplasmatic fraction. The pellet (insoluble fraction) was washed, sonicated, and was used as the nuclear fraction. FGF1 proteins present in each fraction were extracted using Heparin-Sepharose resin and analyzed by SDS-PAGE. The presence of FGF1 was verified by Western blotting. Marker proteins were detected to confirm the purity of the fractions. 


\subsection{Viability and Apoptosis Measurments}

Selected cells, as indicated, were subjected to various stimuli: serum deprivation, etoposide $(50 \mu \mathrm{g} / \mathrm{mL})$, staurosporine $(1 \mu \mathrm{M})$, acinomycin $\mathrm{D}(5 \mu \mathrm{M})$, anisomycin $(10 \mu \mathrm{M})$ in the presence or absence of specific FGFR inhibitor PD173074 (100 nM) for 24-48 h to induce apoptosis. For testing the exogenous effect, the cells were treated with FGF1 variants $(100 \mathrm{ng} / \mathrm{mL})$ and heparin $(10 \mathrm{U} / \mathrm{mL})$. PrestoBlue or AlamarBlue Cell Viability Reagent (Thermo Fisher Scientific, Waltham, MA, USA) were used to measure cell viability according to the manufacturer's protocol. Viability was normalized and expressed as a percentage of the maximum response observed for cells treated with wild type FGF1.

To evaluate caspase3/7 activity, ApoLive-Glo Multiplex Assay (Promega, Madison, WI, USA) was used as previously described [28]. The ratio of caspase3/7 activity to cell viability was normalized toward control cells untreated or untransfected with FGFs referred to as relative caspase $3 / 7$ activity. To evaluate the mitochondrial potential of cells, the Mitopotential Assay Kit (Millipore, Merck, Darmstadt, Germany) was used according to the manufacturer's protocol. The percentage of live, depolarized/live, depolarized/dead, and dead cells in the whole population was measured using the Muse Cell Analyzer (Millipore, Merck, Darmstadt, Germany). In addition, cells were lysed, separated by SDS-PAGE, and analyzed by Western blotting to assess the level of cleaved PARP. All experiments were performed at least three times with at least three replicates in each experiment.

\subsection{Thermal Stability Measurments}

The stability of FGF1 variants was determined from thermal denaturation curves obtained by monitoring the change in ellipticity signal at $227 \mathrm{~nm}$, as described previously $[35,36]$. Data were analyzed using PeakFit software (Jandel Scientific Software, San Rafael, CA, USA), assuming a two-state reversible equilibrium transition.

\subsection{FGF1-Induced Signaling and FGF1 Degradation in Cell-Conditioned Medium}

FGF1-induced signaling was analyzed in serum-starved NIH 3T3 cells, which were stimulated with FGF1 variants at $10 \mathrm{ng} / \mathrm{mL}$ and $100 \mathrm{ng} / \mathrm{mL}$, in the presence of $10 \mathrm{U} / \mathrm{mL}$ heparin for $15 \mathrm{~min}$. In the next step, to assess the stability of FGF1 proteins in the cell medium, FGF1 variants were added to serum-starved NIH3T3 cells at a concentration of $100 \mathrm{ng} / \mathrm{mL}$ in the presence of $10 \mathrm{U} / \mathrm{mL}$ heparin and incubated for $48 \mathrm{~h}$ at $37^{\circ} \mathrm{C}$. The conditioned medium was then transferred to a new set of starved NIH 3T3 cells for $15 \mathrm{~min}$, lysed, separated by SDS-PAGE, and analyzed by Western blotting. Freshly prepared FGF1 solutions at $100 \mathrm{ng} / \mathrm{mL}$ served as positive controls. In parallel, we analyzed the degradation of FGF1 variants $(1 \mu \mathrm{g} / \mathrm{mL})$ after $48 \mathrm{~h}$ in the conditioned medium in the presence of heparin $(10 \mathrm{U} / \mathrm{mL})$ by Western blotting using an anti-FGF1 antibody.

\subsection{Statistical Analyses}

The results are expressed as means $\pm \mathrm{SD}$. For statistical analyses, one-way analysis of variance (ANOVA) with Tukey's posttest was applied using GraphPad Prism 5 (GraphPad Software, San Diego, CA, USA).

\section{Results}

\subsection{Characterisation of Recombinant NLS Variants of the FGF1 Protein}

We have recently reported that the translocation of exogenously administrated FGF1 protects various cell lines from apoptosis independently of FGFR activation [28]. In the present study, we aimed to identify a further mechanism behind this remarkable feature. Due to several indications regarding the biological significance of the nuclear localization of FGF1, we decided to verify its role in the anti-apoptotic response. Earlier studies revealed that NLS deletion resulted in loss of protein stability, protease resistance, and affinity for FGFR [11]. Here, we analyzed a series of NLS mutational variants of FGF1 [7,13] (Figure 1A). Having at our disposal variants of FGF1 with significantly improved stability, we generated an FGF1 mutant combining an NLS deletion and three stabilizing 
substitutions (Q40P, S47I, and H93G) as previously described [34] named $\triangle$ NLS_STAB. Analysis of thermal denaturation curves confirmed very low stability of $\triangle$ NLS variant $\left(\mathrm{T}_{\mathrm{den}}=30.8^{\circ} \mathrm{C}\right)$ as compared with the wild type $\left(\mathrm{T}_{\mathrm{den}}=40.2^{\circ} \mathrm{C}\right)$. Introduction of stabilizing mutations increased the denaturation temperature of $\triangle \mathrm{NLS}$ to $55.3^{\circ} \mathrm{C}$ (Figure 1B). In the next step, we evaluated whether the NLS variants remain functional in cell culture. Thus, NIH 3 T3 cells were starved for $24 \mathrm{~h}$ followed by stimulation with wild type FGF1 or its variants (NLS1, NLS1,2A, $\triangle \mathrm{NLS}$, and $\triangle \mathrm{NLS}$ _STAB) at the concentration of $10 \mathrm{ng} / \mathrm{mL}$ and $100 \mathrm{ng} / \mathrm{mL}$ in the presence of heparin $(10 \mathrm{U} / \mathrm{mL})$. Receptor phosphorylation and activation of the MAPK signaling cascade after $15 \mathrm{~min}$ incubation served as the indicators of protein activity. As expected, the unstable $\triangle$ NLS variant was unable to induce FGFR and ERKs phosphorylation in contrast with the other variants (Figure 1C). Since these results confirm the loss of stability of the $\triangle$ NLS variant of FGF1 followed by loss of activity, this recombinant protein was omitted in later experiments.

We also verified how the introduced mutations affect protein degradation in the cell culture system. Activation of the MAPK signaling cascade was used to determine whether variants remained functional after incubation in culture medium. For this purpose, starved NIH 3T3 cells were stimulated with $100 \mathrm{ng} / \mathrm{mL}$ of fresh FGF1 variants (WT, NLS1, NLS1,2A, $\triangle$ NLS_STAB) in the presence of heparin $(10 \mathrm{U} / \mathrm{mL})$ or FGF1 proteins incubated for $48 \mathrm{~h}$ in conditioned media (Figure 1D). Western blotting analysis showed that all variants retained their ability to bind FGFR and activate FGFR and downstream signaling, as indicated by phosphorylation of ERK1/2. However, the NLS1,2A variant exhibited slightly weaker activity (Figure 1D). Furthermore, we analyzed the degradation of FGF1 variants $(1 \mu \mathrm{g} / \mathrm{mL})$ in NIH 3T3 conditioned medium in the presence of heparin $(10 \mathrm{U} / \mathrm{mL}$ ) after $48 \mathrm{~h}$ (Figure 1E) by Western blotting. We observed that indeed the $\triangle$ NLS variant was labile in medium and rapidly degraded within $48 \mathrm{~h}$, whereas its stable version ( $\triangle$ NLS_STAB) remained almost intact. As expected, the NLS1.2A variant showed increased susceptibility to degradation, which is consistent with its reduced ability to activate downstream signaling.

In the next step, we evaluated the anti-apoptotic potential of exogenously administrated FGF1 variants in NIH3T3 cells. In this experiment, apoptosis was induced by $24 \mathrm{~h}$ serum starvation and then $100 \mathrm{ng} / \mathrm{mL}$ of each variant was added to the cells for $6 \mathrm{~h}$. After that time, caspase $3 / 7$ activity, indicating progression of apoptosis, was measured along with cell viability. The anti-apoptotic response induced through FGFR activation and downstream signaling was virtually the same for all variants tested except for the $\triangle$ NLS mutant (Figure 1F), reflecting their ability to bind and activate the receptor. Overall, our results indicate that all FGF1 NLS variants except $\triangle$ NLS do not degrade and remain functional in the cell culture system.

\subsection{Exogenously Added NLS Variants of FGF1 Deficient in Nuclear Translocation Retain Intracellular Anti-Apoptotic Properties}

Since we had previously demonstrated that translocated FGF1 promote cell survival independently of receptor activation, we tested the competence of NLS variants in inducing an intracellular anti-apoptotic response. First, using U2OSR1 cells, we confirmed again that NLS variants of FGF1 (NLS1, NLS1,2A, and $\triangle$ NLS_STAB) are indeed not translocated to the nucleus but are present in the cytosol upon $6 \mathrm{~h}$ serum starvation. The endosomal proton pomp inhibitor, bafilomycin A1 (BafA1, $10 \mathrm{nM}$ ), which blocks transport from endosomes, was used together with wild-type FGF1 in the negative control. Using subcellular fractionation, wild-type and NLS variants of FGF1 (NLS1, NLS,1,2A and $\triangle$ NLS_STAB) were shown to be present in the membrane and cytosolic fractions, whereas only wild-type FGF1 was found in the nuclear fraction. Detection of $\gamma$-tubulin in the cytosolic fraction served as a control of equal loading (Figure 2A). 
A

\begin{tabular}{|c|c|c|c|c|c|}
\hline \multirow[t]{2}{*}{ Name } & \multicolumn{5}{|c|}{ Mutations of FGF1 } \\
\hline & & 4047 & 93 & 114 & 127 \\
\hline WT & \multirow{2}{*}{\multicolumn{5}{|c|}{ 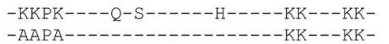 }} \\
\hline NLS1 & & & & & \\
\hline NLS1,2A & \multicolumn{5}{|c|}{$-\mathrm{A} A P A-1-1$} \\
\hline$\triangle N L S$ & \multicolumn{5}{|c|}{ 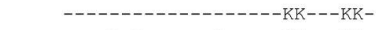 } \\
\hline$\triangle N L S \_S T A B$ & \multicolumn{5}{|c|}{----P-I------G-----KK---KK- } \\
\hline
\end{tabular}

B

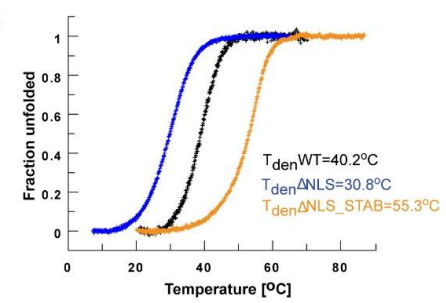

C

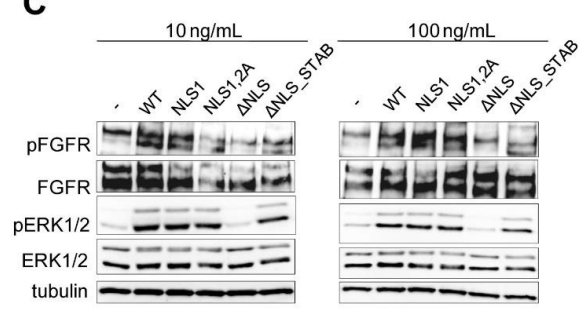

D

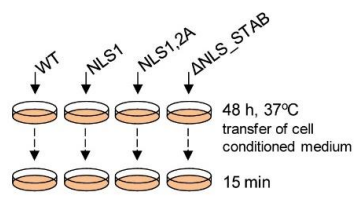

IWB
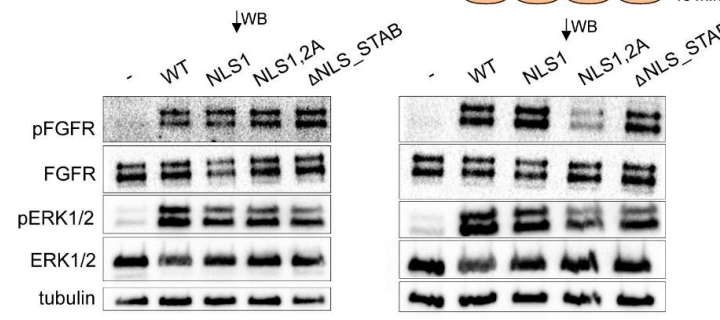

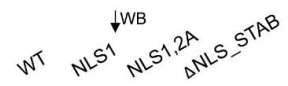

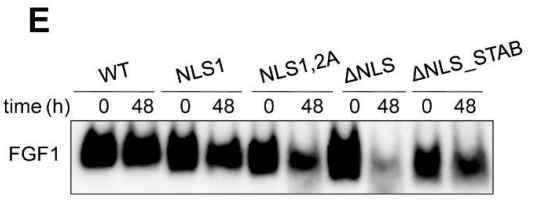

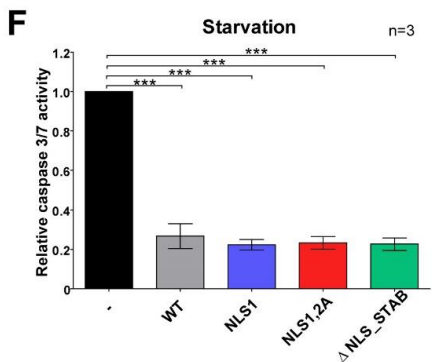

Figure 1. Stability and functional activity of NLS variants of FGF1. (A) Wild type (WT) and mutational variants of FGF1 used in the study. (B) Normalized thermal denaturation curves of FGF1 variants (WT, $\mathrm{NLS}$ and $\triangle \mathrm{NLS}$ STTAB) of FGF1 monitored by ellipticity changes at $228 \mathrm{~nm}$. (C) The biological activity of NLS variants was assessed by analyzing the ability to activate FGF/FGFR signaling by Western blotting. Serum-starved NIH 3T3 cells were stimulated for 15 min with $10 \mathrm{ng} / \mathrm{mL}$ or $100 \mathrm{ng} / \mathrm{mL}$ of FGF1 variants in the presence of $10 \mathrm{U} / \mathrm{mL}$ heparin. (D) Activity of FGF1 variants after $48 \mathrm{~h}$ incubation with NIH 3T3 cells. Serum-starved NIH 3T3 cells were treated for 15 min with either freshly prepared $100 \mathrm{ng} / \mathrm{mL}$ of FGF1 variants and $10 \mathrm{U} / \mathrm{mL}$ heparin or cell-conditioned media after $48 \mathrm{~h}$ incubation with $100 \mathrm{ng} / \mathrm{mL}$ FGF1 variants in the presence of $10 \mathrm{U} / \mathrm{mL}$ heparin. Activation of downstream FGFR signaling was analyzed by Western blotting. (E) Degradation of FGF1 variants in cell-conditioned medium. Freshly prepared solutions of FGF1 variants $(1 \mu \mathrm{g} / \mathrm{mL})$ or $48 \mathrm{~h}$ conditioned media from NIH 3T3 cells stimulated with $1 \mu \mathrm{g} / \mathrm{mL}$ of the respective proteins in the presence of $10 \mathrm{U} / \mathrm{mL}$ heparin were analyzed by Western blotting using polyclonal anti-FGF1 antibodies. (F) For induction of apoptosis, NIH 3T3 cells were subjected to $24 \mathrm{~h}$ serum starvation. Then, the cells were incubated with $100 \mathrm{ng} / \mathrm{mL}$ FGF1 wild type and its mutants. After $6 \mathrm{~h}$, the relative caspase 3/7 activity was determined. Data were normalized to control value and presented as means $\pm \mathrm{SD}$ of three independent experiments. Statistical significance: ${ }^{* *} p \leq 0.001$. 
A

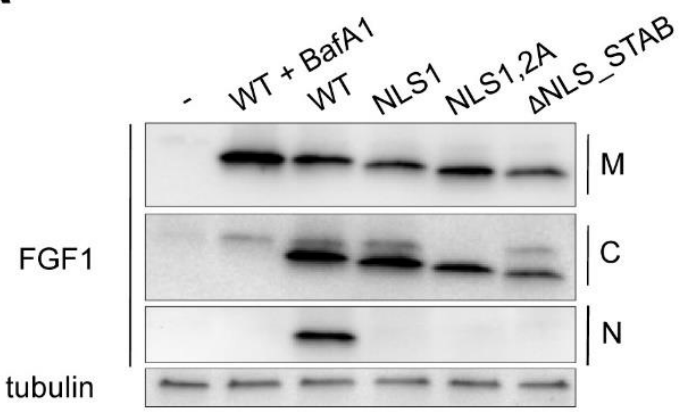

B

U2OSR1

NIH 3T3

Starvation + PD173074

$\mathrm{n}=3$

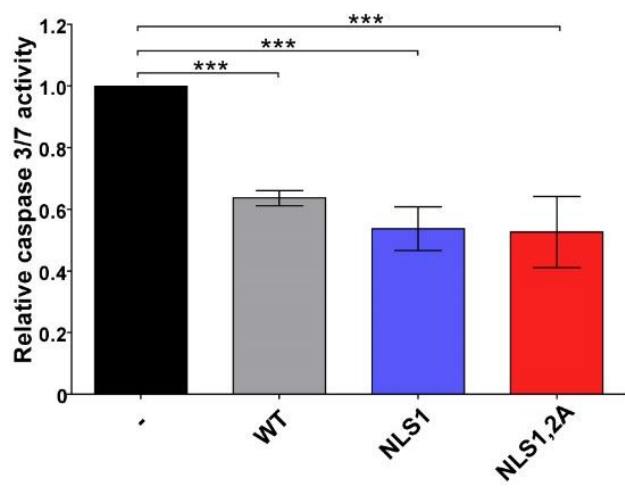

C

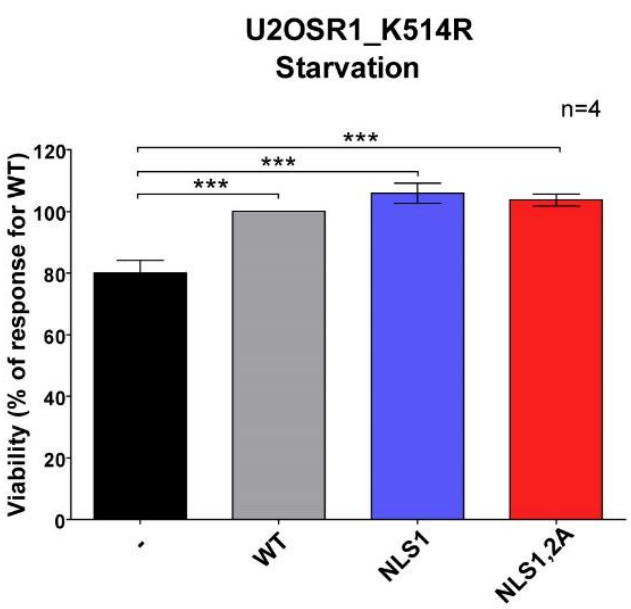

D
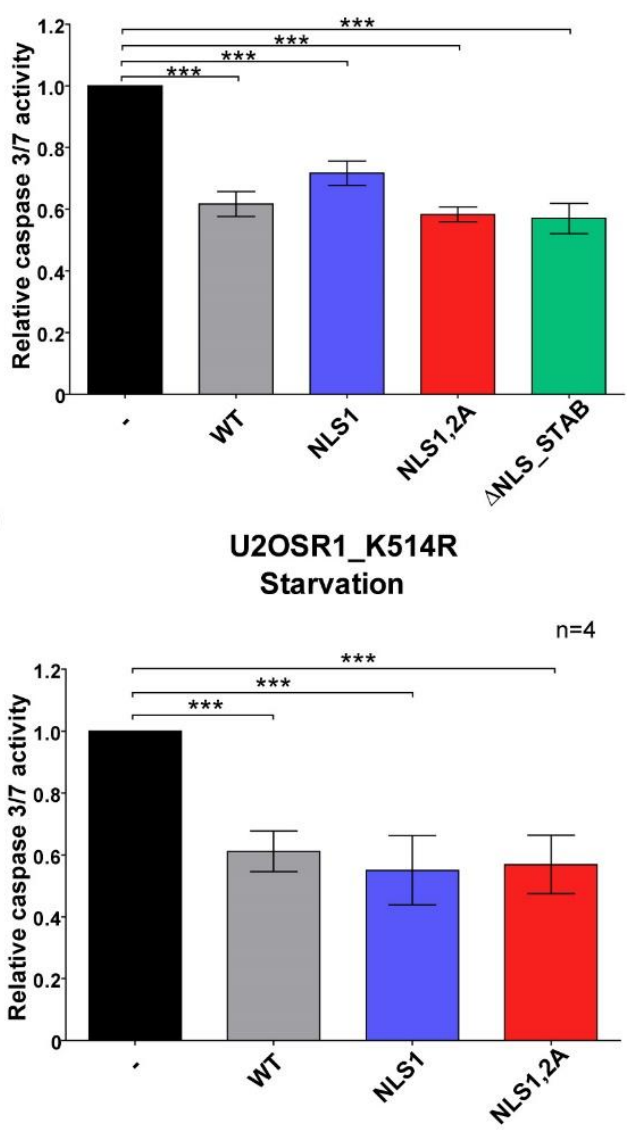

Figure 2. Translocated FGF1 inhibits apoptosis independently of its nuclear localization and receptor activation. (A) NLS variants are effectively translocated to cytosol but are defective in transport to the nucleus. The presence of FGF1 variants in the membrane (M), cytosolic (C) and nuclear $(\mathrm{N})$ fractions was confirmed by subcellular fractionation after $6 \mathrm{~h}$ serum deprivation in U2OSR1 cells. Tubulin in the cytosolic fraction served as an equal loading control. (B) Anti-apoptotic activity of FGF1 variants at $100 \mathrm{ng} / \mathrm{mL}$ in serum-starved cells expressing FGFR1 (U2OSR1 and NIH 3T3) in the presence of potent chemical FGFR inhibitor (100 nM of PD17307), as determined by caspase 3/7 activity measured $16 \mathrm{~h}$ and $6 \mathrm{~h}$ after growth factors' stimulation, respectively. (C,D) Anti-apoptotic activity of FGF1 variants at $100 \mathrm{ng} / \mathrm{mL}$ in serum-starved U2OSR1_K514R cells (U2OS cells stably expressing FGFR1 kinase-dead mutant), as determined by cell viability with Presto Blue reagent (C) and relative caspase 3/7 activity using ApoLive-Glo Multiplex Assay (D) evaluated $48 \mathrm{~h}$ and $16 \mathrm{~h}$ after growth factors' stimulation, respectively. Data were normalized to control values and presented as means \pm SD of three or four independent experiments. Statistical significance: ${ }^{* * *} p \leq 0.001$. 
We then analyzed the anti-apoptotic activities of the translocated NLS variants. To be able to separate the intracellular response from the effect of FGFR and downstream signaling pathways activation, we measured caspase 3/7 activity in two different FGFR1expressing cell lines, mouse NIH 3T3 fibroblasts and human U2OSR1 osteosarcoma cells in the presence of a potent chemical FGFR inhibitor [28]. Apoptosis was induced by $24 \mathrm{~h}$ of starvation, and then $100 \mathrm{ng} / \mathrm{mL}$ of each FGF1 variant (WT, NLS1, NLS1,2A) was added to the cells for $16 \mathrm{~h}$ or $6 \mathrm{~h}$ in the presence of PD173074 in U2OSR1 or NIH3T3 cells, respectively. In this experiment, the caspase $3 / 7$ activity in starved cell was reduced by $40 \%$ for wild-type FGF1 and by approximately 50\% for NLS variants (Figure 2B). The data obtained clearly indicate that anti-apoptotic properties of FGF1 are not related to its nuclear localization.

To ensure that the observed effect is completely independent of FGFR activation, we also used U2OS cells stably transfected with the FGFR1 kinase dead mutant K514R (U2OSR1_K514R), causing complete inactivation of FGFR signaling [28]. Apoptosis was induced in a similar manner as in FGFR-inhibited U2OSR1 cells. Again, all exogenously added FGF1 variants (WT, NLS1, NLS1,2A) were able to halve starvation-induced caspase 3/7 activity in U2OSR1_K514R cells (Figure 2C). We also examined how the anti-apoptotic response translated into cell viability. Cells subjected to $24 \mathrm{~h}$ starvation were treated with $100 \mathrm{ng} / \mathrm{mL}$ of each FGF1 variant for $48 \mathrm{~h}$. There was no difference between the viability of U2OSR1_K514R cells treated with wild type FGF1 or its NLS variants, whereas incubation without growth factors resulted in a decrease in cell viability below $80 \%$. These data show that NLS mutants such as the wild type counteract the progression of apoptosis (Figure 2D). These data are in full agreement with the results obtained in the presence of FGFR inhibitor, confirming that exogenously administered FGF1, as a result of its translocation, protects differentiated cells from apoptosis regardless of receptor activation and its nuclear localization.

\subsection{Wild-Type FGF1 Retains Its Anti-Apoptotic Potential despite Being Prevented from Nuclear Translocation}

To verify the results obtained for NLS mutants, we also knocked-down LRRC59, a protein-mediating nuclear transport of FGF1 (Figure 3A) [22,26], in the human osteosarcoma U2OSR1 cell line constitutively expressing FGFR1. Non-targeting siRNA (scr siRNA) was used as a control. A total of $72 \mathrm{~h}$ after siRNA transfection, the efficiency of silencing was confirmed by Western blotting (Figure 3B). To induce apoptosis, siRNA-transfected cells were subjected to serum deprivation and treated with wild-type FGF1 (100 ng/mL) for $24 \mathrm{~h}$. FGFR activation was chemically inhibited with PD173074 (100 nM) throughout the experiment allowing only the intracellular anti-apoptotic activity of translocated FGF1 to be measured. Analysis of caspase 3/7 activity analysis $16 \mathrm{~h}$ after FGF1 treatment showed that, independent of LRRC59 silencing, wild-type FGF1 was able to counteract apoptosis progression, reducing relative caspase $3 / 7$ activity from 1.0 to 0.45 (Figure $3 \mathrm{C}$ ). This finding confirms that the inability of FGF1 to undergo nuclear import does not limit its anti-apoptotic activity, at least in differentiated cells.

\subsection{Mutations in NLS Sequence of Transiently Expressed FGF1 Do Not Affect Its Pro-Survival Response in Differentiated Cells}

To further evaluate the impact of the NLS sequence on FGF1 anti-apoptotic activity, we transiently transfected U2OS cells with plasmids encoding wild-type FGF1 and its two mutated variants, NLS1 and $\triangle$ NLS. The empty pcDNA3.1 vector was used as a control. In this experiment, a stabilized version of the $\triangle$ NLS mutant was not used to be able to compare the results with previously published reports [33]. First, $48 \mathrm{~h}$ after transfection, FGF1 expression levels were analyzed by Western blotting, confirming the presence of an endogenous pool of wild-type FGF1 as well as its NLS variants (Figure 4A). Cells were then treated for $24 \mathrm{~h}$ with various apoptosis-inducing stimuli: staurosporine $(1 \mu \mathrm{M})$, a potent protein kinase $C$ inhibitor; and anisomycin $(10 \mu \mathrm{M})$, which inhibits protein synthesis. As U2OS cells might express a very low level of FGFRs, a chemical inhibitor of FGFR (PD173074, $100 \mathrm{nM}$ ) was present in the culture media throughout the experiment to ensure 
that the observed effects originated exclusively from intracellular FGF1 proteins and not from secreted growth factors activating signaling. The anti-apoptotic properties of the FGF1 variants were assessed by measuring cell viability using Presto Blue reagent. All apoptosis inducers significantly reduced the viability of U2OS cells transfected with the empty pcDNA3.1 vector compared with FGF1-transfected cells (Figure 4B,C). Both NLS variants behaved virtually the same as wild-type FGF1, efficiently protecting cells from apoptosis. The data obtained clearly indicated that the nuclear localization of FGF1 is not crucial for its pro-survival response.

A

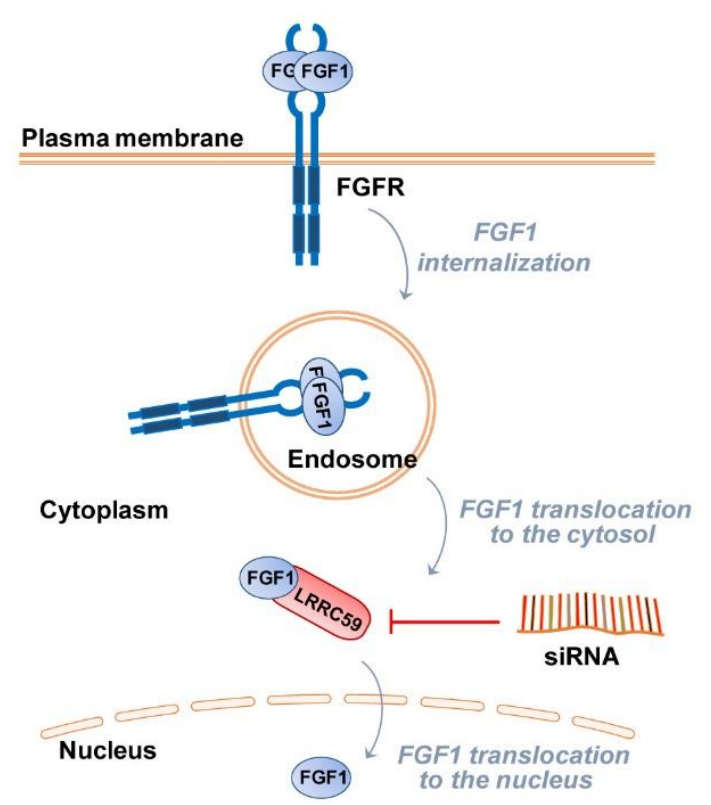

B

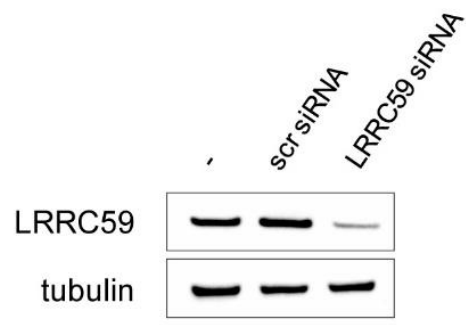

C

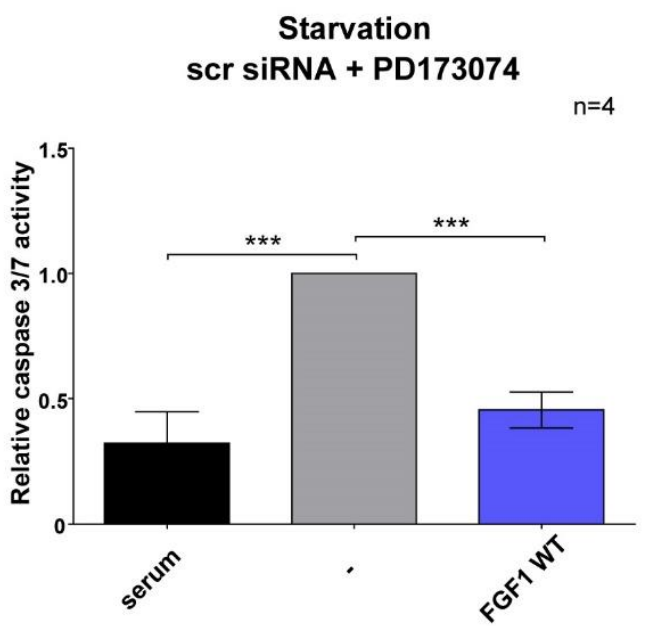

Starvation
LRRC59 siRNA + PD173074
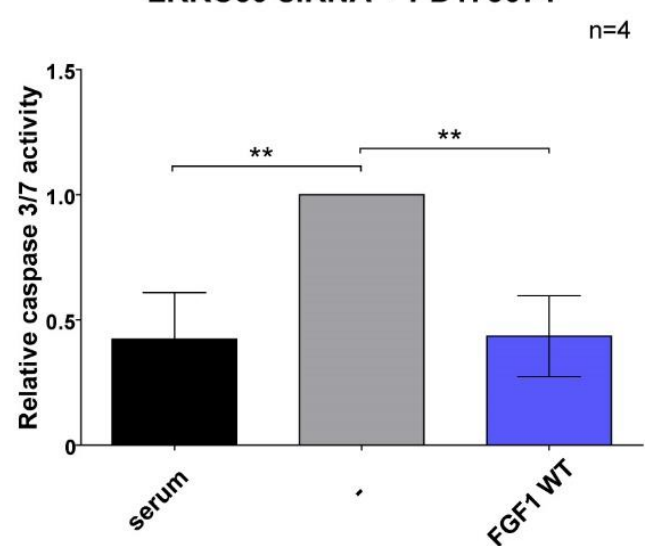

Figure 3. Protective effect of exogenously administrated FGF1 upon LRRC59 silencing. (A) Schematic of mediation of FGF1 nuclear translocation by LRRC59. (B) U2OSR1 cells were transfected with $100 \mathrm{nM}$ of scramble siRNA or siRNA targeted LRRC59. The efficiency of LRRC59 silencing after $72 \mathrm{~h}$ was assessed by Western blotting. (C) For induction of apoptosis $72 \mathrm{~h}$ after silencing, cells were serum starved for $24 \mathrm{~h}$, and then treated with wild-type FGF1 in the presence of FGFR inhibitor (100 nM PD173074). $16 \mathrm{~h}$ later, relative caspase 3/7 activity was determined. Data were normalized to control values and presented as means \pm SD of four independent experiments. Statistical significance: ${ }^{* *} p \leq 0.01,{ }^{* * *} p \leq 0.001$. 
A
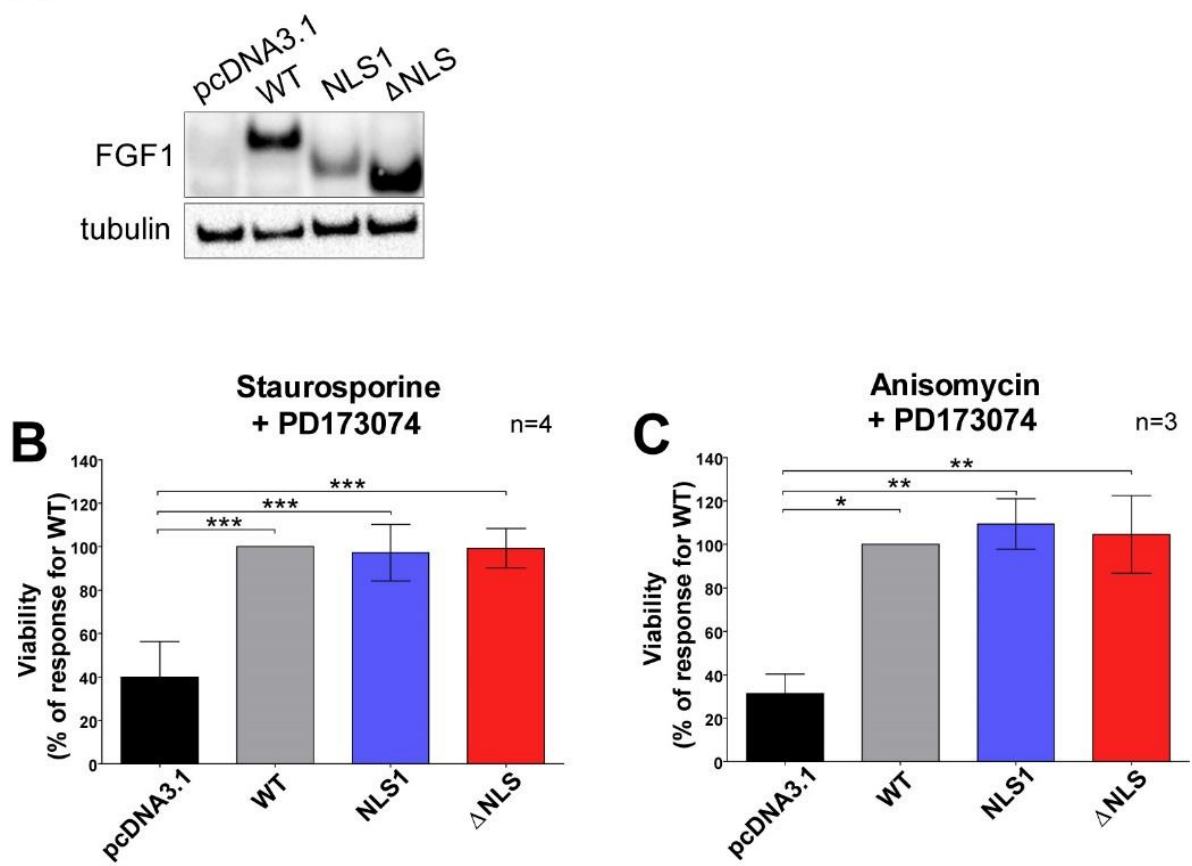

Figure 4. Endogenously expressed FGF1 inhibits apoptosis independently of its nuclear localization. U2OS cells were transiently transected with empty pcDNA3.1 vector or vectors encoding wild type of FGF1 (WT) and its mutated variants (NLS1 and $\triangle$ NLS). (A) The presence of an endogenous FGF1 pool was assessed after $48 \mathrm{~h}$ by Western blotting. To induce apoptosis $48 \mathrm{~h}$ after transfection, cells were subjected for $24 \mathrm{~h}$ to various apoptosis-inducing stimuli: (B) staurosporine $(1 \mu \mathrm{M})$, and (C) anisomycin $(10 \mu \mathrm{M})$ in the presence of the FGFR inhibitor, $100 \mathrm{nM}$ PD173074. Then, the viability of cells was determined using Presto Blue reagent. Data were normalized to control values and presented as means \pm SD of three or four independent experiments. Statistical significance: ${ }^{*} p \leq 0.05$, ** $p \leq 0.01,{ }^{* * *} p \leq 0.001$.

\subsection{Stably Expressed NLS Mutants Exhibit Anti-Apoptotic Activity in U2OS Cells}

To confirm the above results, U2OS cell lines stably expressing FGF1 variants (WT, NLS1, $\triangle$ NLS) were also established. A cell line stably transfected with the empty plasmid pcDNA3.1 served as a control. Expression of the endogenous pool of FGF1 was routinely tested in different cell passages (Figure 5A). To verify again the lack of ability of NLS variants to translocate to the nucleus, we performed subcellular fractionation after $6 \mathrm{~h}$ serum deprivation (Figure 5B). We confirmed the presence of all FGF1 variants in the cytoplasmic fraction, but only the wild-type was present in the nuclear fraction, indicating that NLS1 and $\triangle$ NLS are defective in nuclear localization (Figure 5B). There was no cross contamination between subcellular fractions as determined by Western blotting of the marker proteins-lamin A for the nuclear fraction and ERK1/2 for the cytoplasmic fraction (Figure 5B). 
A

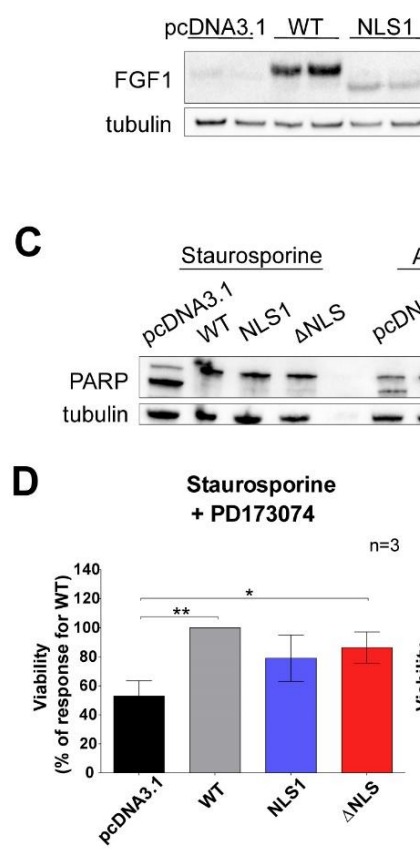

$\mathbf{E}$

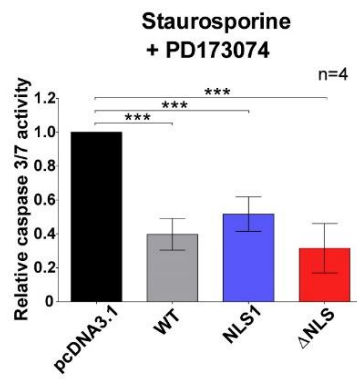

B

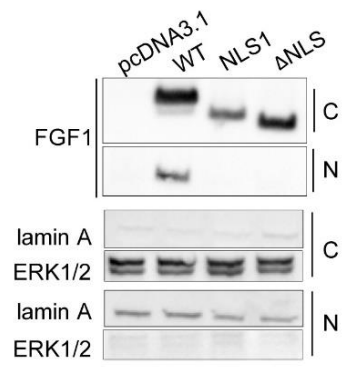

$\mathbf{F}$

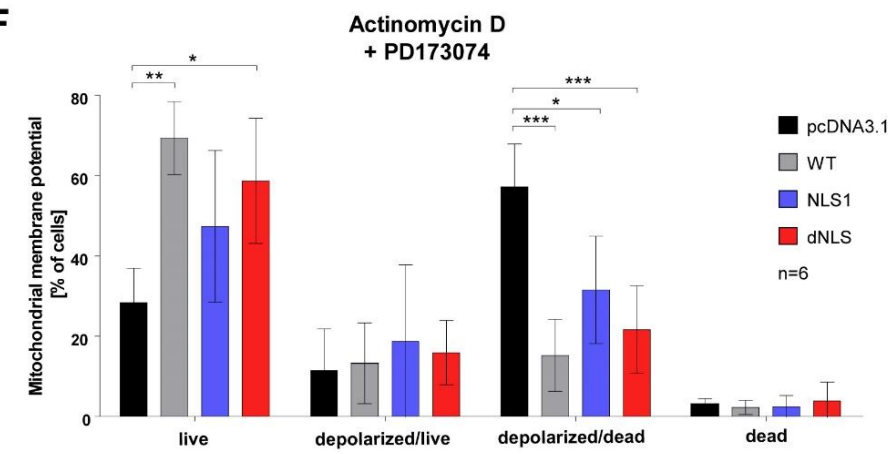

Figure 5. Anti-apoptotic activity of stably expressed FGF1. U2OS cells were stably transfected with vectors encoding wild type FGF1 (WT) and its mutated variants (NLS1 and $\triangle N L S$ ). (A) The presence of pools of individual endogenous FGF1 variants in the lines was verified by Western blotting. (B) The presence of endogenously expressed FGF1 variants in the cytoplasmic (C) and nuclear (N) fractions was confirmed by subcellular fractionation and fraction purity was assessed by detection of the marker proteins, lamin A and ERK1/2 after $6 \mathrm{~h}$ serum starvation. (C) Cell lines were also treated for $6 \mathrm{~h}$ with staurosporine and anisomycin, and PARP cleavage was evaluated by Western blotting. $(\mathrm{D}, \mathrm{E})$ To induce apoptosis, cells were treated with different stimuli: staurosporine $(1 \mu \mathrm{M})$, anisomycin $(10 \mu \mathrm{M})$, and actinomycin D $(5 \mu \mathrm{M})$ in the presence of FGFR inhibitor (PD173074, 100 nM). (D) After $24 \mathrm{~h}$ the viability and (E) caspase 3/7 activity of cells were determined. (F) Mitochondrial membrane potential $(\Delta \Psi \mathrm{m})$ was also measured after $24 \mathrm{~h}$ of actinomycin $\mathrm{D}$ treatment. Data were normalized to control values and presented as means $\pm \mathrm{SD}$ from three to six independent experiments. Statistical significance: ${ }^{*} p \leq 0.05,{ }^{* *} p \leq 0.01,{ }^{* * *} p \leq 0.001$. 
In the next step, we evaluated the progression of apoptosis by verifying Poly (ADPribose) polymerase (PARP) cleavage after $6 \mathrm{~h}$ treatment with staurosporine or anisomycin in stably transfected U2OS cell lines. Western blotting analysis revealed that all cell lines expressing FGF1 variants were characterized by decreased PARP cleavage compared with the control U2OS cell line (Figure 5C). This further confirmed the pro-survival effects of FGF1 regardless of its nuclear localization. We also analyzed the viability of stably transfected cells subjected to various apoptosis-inducing stimuli such as: staurosporine, anisomycin, and actinomycin D, which intercalates into DNA and thus prevents the RNA polymerase progression. Cell viability was assessed after $48 \mathrm{~h}$ using Presto Blue reagent. In all cases, treatment with apoptosis inducers resulted in a decrease in viability of cells transfected with an empty vector (pcDNA3.1) below 60\% of the viability observed for cells stably expressing wild-type FGF1 (Figure 5D). Cells expressing NLS1 or $\triangle$ NLS were characterized by high viability at similar level as wild-type transfected cells (Figure 5D). Furthermore, we determined the anti-apoptotic response in stably transfected U2OS cell lines by measuring caspase $3 / 7$ activity $24 \mathrm{~h}$ after administration of various apoptosis inducers. Again, cell lines expressing all FGF1 variants (WT, NLS1, $\triangle N L S$ ) exhibited significantly reduced caspase $3 / 7$ activity (more than twofold) after treatment with staurosporine, anisomycin or actinomycin D compared with the control cell line (Figure 5E).

Since mitochondrial dysfunction (in particular, the depolarization of the $\Delta \Psi \mathrm{m}$ transmembrane potential) has been shown to be involved in the induction of apoptosis, we decided to measure the mitochondrial potential of stably transfected U2OS cell lines $24 \mathrm{~h}$ after actinomycin D administration. It was observed that the percentage of live cells in cells expressing the WT and $\triangle \mathrm{NLS}$ variants was significantly higher $(62.0 \%$ and $56.6 \%$, respectively) compared with control cells $(23.5 \%)$, as well as the percentage of depolarized/dead cells expressing all FGF1 variants (WT-21.8\%, NLS1-39.6\% and $\Delta$ NLS-23.7\%) was significantly lower compared with the control $(61.7 \%)$ (Figure $5 \mathrm{~F}$ ). These findings indicate that the endogenous expression of all FGF1 variants reduces mitochondrial membrane permeability, preventing its depolarization and consequent release of apoptotic factors leading to cell death.

\section{Discussion}

FGF1 is a classical mitogen that leads to cell growth and proliferation through FGF receptor binding and activation. However, under stress conditions, this protein additionally has the ability to translocate into the cell interior in a receptor-mediated manner (via FGFR1 and FGFR4), but independently of FGFR activation [17,18]. For many years, the role of intracellular FGF1 was unclear. We have recently shown that translocated FGF1 is able to inhibit apoptosis and promote cell survival even when FGFR tyrosine kinase is completely inactive [28]. Despite the presence of potent FGFR inhibitors or a FGFR kinase inactivating mutation, exogenously added FGF1 is able to protect the cell from apoptosis. In accordance, the presence of translocation inhibitors (endosomal proton pumps or HSP90 inhibitors) prevents pro-survival action of FGF1 indicating that the intracellular pool of FGF1 is responsible for the anti-apoptotic effect [28]. FGF1, crossing the cell membrane, reaches the cytosol and then the cell nucleus [6]. FGF1 has been shown to contain two NLS sequences that are required for its nuclear transport [13]. In this study, we decided to verify whether the nuclear localization of FGF1 is responsible for its anti-apoptotic properties. To investigate the role of the NLS sequence in the anti-apoptotic response of FGF1, we generated a series of its mutational variants-NLS1, NLS1,2A, $\triangle N L S, \triangle N L S \_S T A B$.

Since the $\triangle$ NLS mutant showed lower biological activity in several previously published papers $[7,8,37]$, we decided to check its stability and folding. The deletion of four amino acid residues from the N-terminus of FGF1 resulted in a strong reduction in its thermodynamic stability. The denaturation temperature was close to $30.8^{\circ} \mathrm{C}$, indicating that at physiological temperature the protein is almost completely unfolded. When FGF1 is not in its native conformation, the binding and translocation process may be impaired. Therefore, for the recombinant protein experiments, instead of $\Delta \mathrm{NLS}$ mutant we decided to 
use its stabilized version ( $\triangle$ NLS_STAB), which was generated by introduction of three stabilizing substitutions thoroughly characterized by us [34]. Increased stability of $\triangle$ NLS_STAB variant provided the proper binding and activation of the FGF receptor but did not affect its intracellular localization. In the lysine-substituted NLS mutant (NLS1), the proteins showed similar thermal stability and biological activity as the wild type [12]. The absence of the NLS sequence meant that it was not transported into the nucleus after reaching the cytosol. Using subcellular fractionation, we confirmed the results of previous work that NLS variants of FGF1 mutations (NLS1, NLS1,2A, $\triangle$ NLS_STAB) do not undergo nuclear translocation in contrast to the wild type [13].

In a subsequent step, using chemical receptor inhibition (PD17307) or a kinase dead FGFR1 mutant cell line [38,39], we found that exogenously administered NLS mutants exhibited anti-apoptotic properties in NIH 3T3 and U2OS cells expressing FGFR1 after serum deprivation, independently of receptor activation. These data strongly suggested to us that nuclear localization of FGF1 is not required for its protective effect.

We observed similar pro-survival effects in U2OSR1 cells transfected with vectors encoding NLS1 and $\triangle$ NLS and then treated with various apoptosis inducers: staurosporine, anisomycin and actinomycin D in the presence of FGFR chemical inhibitor. Using cell lines stably expressing NLS variants (NLS1 and $\triangle$ NLS) of FGF1, we confirmed their anti-apoptotic properties. NLS mutants, such as wild-type FGF1, were able to significantly improve cell viability and inhibit caspase 3/7 activity when treated with different apoptosis-inducing stimuli. Furthermore, changes in mitochondrial membrane potential were observed in cells treated with actinomycin D, reflecting the progression of apoptosis. Stable expression of NLS variants resulted in a significant reduction in the pool of depolarized/dead U2OSR1 cells. Furthermore, NLS variants prevented the proteolytic cleavage of PARP. In all these experiments, we eliminated the potential anti-apoptotic effect of FGF1 originating from receptor activation (for example due to the release of FGF1 after cell disruption) with the specific FGFR inhibitor PD17307. In conclusion, these data clearly indicate that the nuclear localization of FGF1 is not important for its pro-survival response.

The LRRC59 protein is one of the intracellular binding partners of FGF1 [22]. Furthermore, LRRC59 has been shown to be essential for nuclear import of FGF1, which is mediated by Ran GTPase and $\alpha 1$ and $\beta 1$ karyopherins [26]. Therefore, to verify the role of nuclear localization without the use of FGF1 mutants, we decided to perform apoptosis experiments when LRRC59 was knocked-down with siRNA. After LRRC59 silencing in U2OSR1 cells, FGF1 was still able to inhibit apoptosis progression induced by starvation. This result indirectly confirms that the presence of FGF1 in the nucleus is not necessary for its protective function.

Interestingly, in the context of low thermodynamic stability, in our hands, the $\triangle$ NLS mutant retained its anti-apoptotic properties when expressed inside U2OS cells. This may be due to the fact that this variant was able to adopt the proper, native conformation, thanks to the specific chaperones and other interacting partners present in the differentiated cell.

A previous study that linked the NLS sequence to the neurotrophic activity and prosurvival response of FGF1 [33] is in contrast to our results obtained in differentiated cell models. Rodriguez-Enfedaque and co-workers showed that the transfection of undifferentiated rat pheochromocytoma PC12 cells with a vector encoding the $\triangle$ NLS variant of FGF1 resulted in the inhibition of $\mathrm{p} 53$-dependent protection against cell death, and neurothrophic activity compared with the wild type [33]. The fact that deletion of the NLS sequence results in a significant loss of protein stability and protein unfolding may explain this discrepancy and impaired biological activity of the $\triangle$ NLS variant in some cell types [11], especially undifferentiated cells.

As our data are in conflict with results previously obtained in PC12 cells [33], we decided to include this cell line in our study. PC12 cells were transfected with vectors encoding the NLS1 or $\triangle$ NLS variant and the progression of apoptosis induced by etoposide treatment was evaluated. We obtained the same results as in Renaud's group-with both 
NLS variants, cell viability was reduced, and caspase $3 / 7$ activity was increased compared with cells transfected with wild-type FGF1 (Supplementary Figure S1A).

We assumed that the difference between the data obtained might be due to the nature of the various cell lines at different levels of differentiation. Therefore, we repeated the experiment performed for PC12 cells using a second undifferentiated cell line, human embryonic kidney cells HEK-293 (Supplementary Figure S1B), and again, the data obtained confirmed the previous results, showing that FGF1 transport to the nucleus is essential for its anti-apoptotic activity. Since we have shown that the nuclear localization of FGF1 (whether translocated or ectopically expressed) is not responsible for its anti-apoptotic response in differentiated cells, such as human osteosarcoma (U2OS) and mouse fibroblasts (NIH 3T3), we hypothesize that the mode of action of FGF1 is more complex and may vary depending on the cell type it affects. It also does not appear to be dependent on the level of FGFR receptors, nor the pool of endogenous FGF1, which was below the detection level in all cells analyzed (Supplementary Figure S2A,B). It is also possible that the observed differences between differentiated and undifferentiated cells in their response to the labile $\triangle$ NLS variant are due to the different expression levels of the FGF1 partner proteins and thus the different stability of their complexes with the growth factor.

Taking together, our results indicate that nuclear localization of FGF1 is not critical for its intracellular anti-apoptotic activity in differentiated cells and suggest that the mechanism of stress response varies with the level of cell differentiation. The exact mechanism of the anti-apoptotic activity of FGF1 is still unknown. However, there are indications that intracellular binding partners of FGF1, such as p53, may regulate its intracellular activity $[30,33]$. It is highly likely that interactions with other proteins involved in apoptosis, located in the cytoplasm, are responsible for the anti-apoptotic properties of FGF1. Since targeting the FGF/FGFR axis might be promising for both regenerative medicine and cancer therapies [40], our findings highlight the complexity of the mechanism of FGF1's protective action and the need for its further investigation.

Supplementary Materials: The following are available online at https:/ /www.mdpi.com/article/10 .3390 /cells11030522/s1, Figure S1 FGF1 anti-apoptotic activity depending on its nuclear localization in undifferentiated cells. Figure S2 Characteristics of the cell lines used in the study.

Author Contributions: Conceptualization, M.Z.; methodology, A.L., K.D.S., A.C., A.S., A.W.; validation, A.L., K.D.S., A.C.; formal analysis, K.D.S.; investigation, A.L., K.D.S., A.C., A.S., A.W.; resources, M.Z.; data curation, K.D.S.; writing—original draft preparation, K.D.S., M.Z.; writing—review and editing, A.L., K.D.S., A.C., A.S., J.O., M.Z.; visualization, K.D.S.; supervision, M.Z.; project administration, M.Z.; funding acquisition, M.Z. All authors have read and agreed to the published version of the manuscript.

Funding: This research was funded by National Science Centre, grant number Sonata Bis 2015/18/E/ NZ3/00501.

Acknowledgments: We gratefully thank Marta Minkiewicz and Dagmara Jakubowska for their excellent technical assistance.

Conflicts of Interest: The authors declare no conflict of interest.

\author{
Abbreviations \\ BafA1 Bafilomycin A1 \\ FGF1 fibroblast growth factor 1 \\ FGFR fibroblast growth factor receptor \\ NLS nuclear localization sequence \\ NES nuclear export sequence \\ PARP Poly (ADP-ribose) polymerase \\ WT wild type
}




\section{References}

1. Powers, C.J.; McLeskey, S.W.; Wellstein, A. Fibroblast growth factors, their receptors and signaling. Endocr. Relat. Cancer 2000, 7, 165-197. [CrossRef] [PubMed]

2. Lemmon, M.A.; Schlessinger, J. Cell signaling by receptor tyrosine kinases. Cell 2010, 141, 1117-1134. [CrossRef] [PubMed]

3. Eswarakumar, V.P.; Lax, I.; Schlessinger, J. Cellular signaling by fibroblast growth factor receptors. Cytokine Growth Factor Rev. 2005, 16, 139-149. [CrossRef]

4. Imamura, T.; Oka, S.; Tanahashi, T.; Okita, Y. Cell cycle-dependent nuclear localization of exogenously added fibroblast growth factor-1 in BALB/c 3T3 and human vascular endothelial cells. Exp. Cell Res. 1994, 215, 363-372. [CrossRef]

5. Wiedlocha, A.; Falnes, P.O.; Madshus, I.H.; Sandvig, K.; Olsnes, S. Dual mode of signal transduction by externally added acidic fibroblast growth factor. Cell 1994, 76, 1039-1051. [CrossRef]

6. Olsnes, S.; Klingenberg, O.; Wiedlocha, A. Transport of exogenous growth factors and cytokines to the cytosol and to the nucleus. Physiol. Rev. 2003, 83, 163-182. [CrossRef] [PubMed]

7. Imamura, T.; Engleka, K.; Zhan, X.; Tokita, Y.; Forough, R.; Roeder, D.; Jackson, A.; Maier, J.A.; Hla, T.; Maciag, T. Recovery of mitogenic activity of a growth factor mutant with a nuclear translocation sequence. Science 1990, 249, 1567-1570. [CrossRef]

8. Imamura, T.; Tokita, Y.; Mitsui, Y. Identification of a heparin-binding growth factor-1 nuclear translocation sequence by deletion mutation analysis. J. Biol. Chem. 1992, 267, 5676-5679. [CrossRef]

9. Dang, C.V.; Lee, W.M. Nuclear and nucleolar targeting sequences of c-erb-A, c-myb, N-myc, p53, HSP70, and HIV tat proteins. J. Biol. Chem. 1989, 264, 18019-18023. [CrossRef]

10. Silver, P.; Goodson, H. Nuclear protein transport. Crit. Rev. Biochem. Mol. Biol. 1989, 24, 419-435. [CrossRef]

11. Luo, Y.; Gabriel, J.L.; Wang, F.; Zhan, X.; Maciag, T.; Kan, M.; McKeehan, W.L. Molecular modeling and deletion mutagenesis implicate the nuclear translocation sequence in structural integrity of fibroblast growth factor-1. J. Biol. Chem. 1996, 271, 26876-26883. [CrossRef]

12. Friedman, S.; Zhan, X.; Maciag, T. Mutagenesis of the nuclear localization sequence in EGF-1 alters protein stability but not mitogenic activity. Biochem. Biophys. Res. Commun. 1994, 198, 1203-1208. [CrossRef] [PubMed]

13. Wesche, J.; Malecki, J.; Wiedlocha, A.; Ehsani, M.; Marcinkowska, E.; Nilsen, T.; Olsnes, S. Two nuclear localization signals required for transport from the cytosol to the nucleus of externally added FGF-1 translocated into cells. Biochemistry 2005, 44, 6071-6080. [CrossRef]

14. Malecki, J.; Wesche, J.; Skjerpen, C.S.; Wiedlocha, A.; Olsnes, S. Translocation of FGF-1 and FGF-2 across vesicular membranes occurs during G1-phase by a common mechanism. Mol. Biol. Cell 2004, 15, 801-814. [CrossRef] [PubMed]

15. Sorensen, V.; Wiedlocha, A.; Haugsten, E.M.; Khnykin, D.; Wesche, J.; Olsnes, S. Different abilities of the four FGFRs to mediate FGF-1 translocation are linked to differences in the receptor C-terminal tail. J. Cell Sci. 2006, 119, 4332-4341. [CrossRef]

16. Sorensen, V.; Zhen, Y.; Zakrzewska, M.; Haugsten, E.M.; Walchli, S.; Nilsen, T.; Olsnes, S.; Wiedlocha, A. Phosphorylation of fibroblast growth factor (FGF) receptor 1 at Ser777 by p38 mitogen-activated protein kinase regulates translocation of exogenous FGF1 to the cytosol and nucleus. Mol. Cell. Biol. 2008, 28, 4129-4141. [CrossRef]

17. Klingenberg, O.; Wiedocha, A.; Citores, L.; Olsnes, S. Requirement of phosphatidylinositol 3-kinase activity for translocation of exogenous aFGF to the cytosol and nucleus. J. Biol. Chem. 2000, 275, 11972-11980. [CrossRef] [PubMed]

18. Zakrzewska, M.; Sorensen, V.; Jin, Y.; Wiedlocha, A.; Olsnes, S. Translocation of exogenous FGF1 into cytosol and nucleus is a periodic event independent of receptor kinase activity. Exp. Cell Res. 2011, 317, 1005-1015. [CrossRef]

19. Malecki, J.; Wiedlocha, A.; Wesche, J.; Olsnes, S. Vesicle transmembrane potential is required for translocation to the cytosol of externally added FGF-1. EMBO J. 2002, 21, 4480-4490. [CrossRef]

20. Belkowski, S.M.; Levine, J.E.; Prystowsky, M.B. Requirement of PI3-kinase activity for the nuclear transport of prolactin in cloned murine T lymphocytes. J. Neuroimmunol. 1999, 94, 40-47. [CrossRef]

21. Wesche, J.; Malecki, J.; Wiedlocha, A.; Skjerpen, C.S.; Claus, P.; Olsnes, S. FGF-1 and FGF-2 require the cytosolic chaperone Hsp90 for translocation into the cytosol and the cell nucleus. J. Biol. Chem. 2006, 281, 11405-11412. [CrossRef]

22. Skjerpen, C.S.; Wesche, J.; Olsnes, S. Identification of ribosome-binding protein p34 as an intracellular protein that binds acidic fibroblast growth factor. J. Biol. Chem. 2002, 277, 23864-23871. [CrossRef] [PubMed]

23. Wang, F.; Yang, L.; Shi, L.; Li, Q.; Zhang, G.; Wu, J.; Zheng, J.; Jiao, B. Nuclear translocation of fibroblast growth factor-2 (FGF2) is regulated by Karyopherin-beta2 and Ran GTPase in human glioblastoma cells. Oncotarget 2015, 6, 21468-21478. [CrossRef] [PubMed]

24. Yamada, K.; Miyamoto, Y.; Tsujii, A.; Moriyama, T.; Ikuno, Y.; Shiromizu, T.; Serada, S.; Fujimoto, M.; Tomonaga, T.; Naka, T.; et al. Cell surface localization of importin alpha1/KPNA2 affects cancer cell proliferation by regulating FGF1 signalling. Sci. Rep. 2016, 6, 21410. [CrossRef]

25. Nilsen, T.; Rosendal, K.R.; Sorensen, V.; Wesche, J.; Olsnes, S.; Wiedlocha, A. A nuclear export sequence located on a beta-strand in fibroblast growth factor-1. J. Biol. Chem. 2007, 282, 26245-26256. [CrossRef] [PubMed]

26. Zhen, Y.; Sorensen, V.; Skjerpen, C.S.; Haugsten, E.M.; Jin, Y.; Walchli, S.; Olsnes, S.; Wiedlocha, A. Nuclear import of exogenous FGF1 requires the ER-protein LRRC59 and the importins Kpnalpha1 and Kpnbeta1. Traffic 2012, 13, 650-664. [CrossRef] [PubMed]

27. Wiedlocha, A.; Nilsen, T.; Wesche, J.; Sorensen, V.; Malecki, J.; Marcinkowska, E.; Olsnes, S. Phosphorylation-regulated nucleocytoplasmic trafficking of internalized fibroblast growth factor-1. Mol. Biol. Cell 2005, 16, 794-810. [CrossRef] [PubMed] 
28. Kostas, M.; Lampart, A.; Bober, J.; Wiedlocha, A.; Tomala, J.; Krowarsch, D.; Otlewski, J.; Zakrzewska, M. Translocation of Exogenous FGF1 and FGF2 Protects the Cell against Apoptosis Independently of Receptor Activation. J. Mol. Biol. 2018, 430, 4087-4101. [CrossRef] [PubMed]

29. Renaud, F.; Desset, S.; Oliver, L.; Gimenez-Gallego, G.; Van Obberghen, E.; Courtois, Y.; Laurent, M. The neurotrophic activity of fibroblast growth factor 1 (FGF1) depends on endogenous FGF1 expression and is independent of the mitogen-activated protein kinase cascade pathway. J. Biol. Chem. 1996, 271, 2801-2811. [CrossRef]

30. Bouleau, S.; Grimal, H.; Rincheval, V.; Godefroy, N.; Mignotte, B.; Vayssiere, J.L.; Renaud, F. FGF1 inhibits p53-dependent apoptosis and cell cycle arrest via an intracrine pathway. Oncogene 2005, 24, 7839-7849. [CrossRef]

31. Bouleau, S.; Parvu-Ferecatu, I.; Rodriguez-Enfedaque, A.; Rincheval, V.; Grimal, H.; Mignotte, B.; Vayssiere, J.L.; Renaud, F. Fibroblast Growth Factor 1 inhibits p53-dependent apoptosis in PC12 cells. Apoptosis Int. J. Program. Cell Death 2007, 12, 1377-1387. [CrossRef] [PubMed]

32. Delmas, E.; Jah, N.; Pirou, C.; Bouleau, S.; Le Floch, N.; Vayssiere, J.L.; Mignotte, B.; Renaud, F. FGF1 C-terminal domain and phosphorylation regulate intracrine FGF1 signaling for its neurotrophic and anti-apoptotic activities. Cell Death Dis. 2016, 7, e2079. [CrossRef] [PubMed]

33. Rodriguez-Enfedaque, A.; Bouleau, S.; Laurent, M.; Courtois, Y.; Mignotte, B.; Vayssiere, J.L.; Renaud, F. FGF1 nuclear translocation is required for both its neurotrophic activity and its p53-dependent apoptosis protection. Biochim. Biophys. Acta 2009, 1793, 1719-1727. [CrossRef] [PubMed]

34. Zakrzewska, M.; Wiedlocha, A.; Szlachcic, A.; Krowarsch, D.; Otlewski, J.; Olsnes, S. Increased protein stability of FGF1 can compensate for its reduced affinity for heparin. J. Biol. Chem. 2009, 284, 25388-25403. [CrossRef]

35. Zakrzewska, M.; Krowarsch, D.; Wiedlocha, A.; Olsnes, S.; Otlewski, J. Highly stable mutants of human fibroblast growth factor-1 exhibit prolonged biological action. J. Mol. Biol. 2005, 352, 860-875. [CrossRef] [PubMed]

36. Szlachcic, A.; Sochacka, M.; Czyrek, A.; Opalinski, L.; Krowarsch, D.; Otlewski, J.; Zakrzewska, M. Low Stability of IntegrinBinding Deficient Mutant of FGF1 Restricts Its Biological Activity. Cells 2019, 8, 899. [CrossRef]

37. Suh, J.M.; Jonker, J.W.; Ahmadian, M.; Goetz, R.; Lackey, D.; Osborn, O.; Huang, Z.; Liu, W.; Yoshihara, E.; van Dijk, T.H.; et al. Endocrinization of FGF1 produces a neomorphic and potent insulin sensitizer. Nature 2014, 513, 436-439. [CrossRef]

38. Low, B.C.; Lim, Y.P.; Lim, J.; Wong, E.S.; Guy, G.R. Tyrosine phosphorylation of the Bcl-2-associated protein BNIP-2 by fibroblast growth factor receptor-1 prevents its binding to Cdc42GAP and Cdc42. J. Biol. Chem. 1999, 274, 33123-33130. [CrossRef]

39. Roumiantsev, S.; Krause, D.S.; Neumann, C.A.; Dimitri, C.A.; Asiedu, F.; Cross, N.C.; Van Etten, R.A. Distinct stem cell myeloproliferative/T lymphoma syndromes induced by ZNF198-FGFR1 and BCR-FGFR1 fusion genes from 8p11 translocations. Cancer Cell 2004, 5, 287-298. [CrossRef]

40. Xie, Y.; Su, N.; Yang, J.; Tan, Q.; Huang, S.; Jin, M.; Ni, Z.; Zhang, B.; Zhang, D.; Luo, F.; et al. FGF/FGFR signaling in health and disease. Signal Transduct. Target. Ther. 2020, 5, 181. [CrossRef] 